\title{
Caracterização do hidrotermalismo "verde" em rochas siliciclásticas do Grupo Pajeú (Supergrupo Oliveira dos Brejinhos), Espinhaço Setentrional, Bahia
}

\author{
André Danderfer ${ }^{1}$, Newton Souza Gomes ${ }^{1}$ \& Kelly Cristina Alves ${ }^{2}$
}

\begin{abstract}
Resumo O Grupo Pajeú constitui a unidade superior do Supergrupo Oliveira dos Brejinhos ocorrendo na borda leste da Serra do Espinhaço Setentrional no estado da Bahia. Essa unidade corresponde ao preenchimento de uma bacia do tipo rifte, durante um dos estágios evolutivos da Bacia Espinhaço no norte do Craton São Francisco. A Formação Riacho Fundo, unidade basal do Grupo Pajeú, foi depositada predominantemente por sistemas de leques aluviais e de rios anastomosados, submetidos ao retrabalhamento eólico. Subsequentemente, esta sucessão foi recoberta pelos sedimentos da Formação Ipuçaba, depositados num sistema retrogradacional lacustrino-deltáico. O estágio final do preenchimento da bacia na parte sul foi caracterizado pela ocorrência de vulcanismo intermediário a ácido associado à deposição de sedimentos clásticos e vulcanoclásticos da Formação Bomba, de idade eo-calamiana. De forma notável no segmento norte da bacia, a pilha sedimentar do Grupo Pajeú foi afetada por um evento hidrotermal, responsável por conferir uma coloração verde às rochas epiclásticas das formações Riacho Fundo (arenitos e conglomerados) e Ipuçaba (arenitos, pelitos e diamictitos). As rochas mais antigas do embasamento, representadas por gnaisses do Complexo Paramirim foram igualmente afetadas por este evento, já as sucessões sedimentares superiores não exibem efeitos de alteração hidrotermal, à exceção dos arenitos eólicos basais da Formação Bom Retiro que capeiam toda a extensão do Grupo Pajeú. Investigações microscópicas e por meio de microssonda permitiram caracterizar uma paragênese mineral rara que inclui granada, anfibólio, epídoto, titanita, quartzo e albita. A origem do evento hidrotermal assim como da paragênese mineral a ele associado poderia ser relacionado com o estágio final de formação do rifte Pajeú, tendo como fonte de fluidos o magmatismo que deu origem às rochas vulcânicas da Formação Bomba.
\end{abstract}

Palavras-chave: Cráton São Francisco, Bacia Espinhaço, petrogênese, hidrotermalismo, Grupo Pajeú.

\begin{abstract}
Characterization of the "green" hydrothermalism on siliciclastic rocks of the Pajeú Group (Oliveira dos Brejinhos Supergroup), northern Espinhaço, Bahia, Brazil. The Pajeú Group defines the upper interval of the Oliveira dos Brejinhos Supergroup, occurring along the eastern border of the Northern Espinhaço Range in Bahia State. This unit records the infilling of a typical rift basin, formed during one of the evolutionary events of the Espinhaço basin in the São Francisco Craton northern part. The basal succession (Riacho Fundo Formation) was deposited mainly through alluvial fans systems, braided river and "dry" eolic system. Subsequently this sequence was covered by a retrogradational delta-lacustrine system (Ipuçaba Formation). In the southern, the basin infilling is finalized by an intermediate to acid volcanism and associated clastic and volcanoclastic rocks (Bomba Formation) of Eocalymian age. Distinctly in the northern segment of the basin, the sedimentary sequence of the Pajeú Group was affected by a hydrothermal event that gave a green color to the epiclastic rocks, including sandstones and conglomerates of the Riacho Fundo Formation and sandstones, mudstones and diamictites of the Ipuçaba Formation. The oldest rocks of the basement (gneisses of the Paramirim Complex) were equally affected by this event, although the upper sedimentary successions do not show effects of hydrothermal alteration, except for the basal eolian sandstones of the Bom Retiro Formation which cover the full extent of the Pajeú Group. Microscopic and microprobe studies allowed the identification of a rare mineral paragenesis that includes garnet, amphibole, epidote, titanite, quartz and albite. The origin of hydrothermal event as well as the associated mineral paragenesis could be related to the final stage of Pajeú rift formation. The source of the fluid is probably the magmatism that gave rise to the volcanic rocks of the Bomba. Formation.
\end{abstract}

Keywords: São Francisco Craton, Espinhaço Basin, petrogenesis, hydrothermalism, Pajeú Group.

INTRODUÇÃO A província geofisiográfica do Espinhaço Setentrional está situada na porção central da Bahia, separada a leste da Chapada Diamantina pelo vale do Paramirim. Dentro do contexto geotectônico esta província localiza-se ao longo da porção ocidental do Aulacógeno Espinhaço (Moutinho da Costa \& Inda

1 - Departamento de Geologia, Universidade Federal de Ouro Preto, Ouro Preto (MG), Brasil.

E-mail: andre@degeo.ufop.br, newton@degeo.ufop.br

2 - Departamento de Geologia, Universidade Federal de Ouro Preto, Iniciação Científica - PIBIC, Ouro Preto (MG), Brasil.

E-mail:kelcrisalves@yahoo.com.br. 
1981) ou do corredor de deformação do Paramirim (Alkmim et al. 1993), definindo uma zona estruturada segundo NNW-SSE que atravessa o norte do Craton São Francisco (Almeida 1977, Fig. 1). As diversas bacias que ocorrem nesse segmento foram descritas por Danderfer \& Dardenne (2002), dentre as quais se destaca o rifte Pajeú de idade Neoestateriana a Eocalimiana (Danderfer et al. 2009).

$\mathrm{O}$ rifte Pajeú é preenchido por uma sequência vulcano-sedimentar - o Grupo Pajeú - que define o intervalo basal do Espinhaço Setentrional e parte superior do Supergrupo Oliveira dos Brejinhos (Danderfer \& Dardenne 2002). Esta unidade foi identificada e mapeada no "Projeto Chumbo" como Formação Pajeú (Kaul 1970 apud Schobbenhaus 1972) e, posteriormente, cartogra- fada e descrita no Projeto Santo Onofre, por Moutinho da Costa e Silva (1980). A natureza da sedimentação é predominantemente siliciclástica, com conglomerados, arenitos e pelitos formando o seu arcabouço principal, além de rochas vulcânicas. Em geral, as rochas apresentam coloração esverdeada associada ao desenvolvimento de uma paragênese hidrotermal, denominada por Danderfer (2000) de hidrotermalismo "verde".

Este trabalho descreve os aspectos litológicos e estruturais observados em campo e as características petrográficas relacionadas com esse hidrotermalismo, tecendo considerações sobre a sua origem e significado geológico. Os estudos foram conduzidos na porção norte do aulacógeno Espinhaço onde a deformação e o metamorfismo são de muito baixa magnitude e inten-

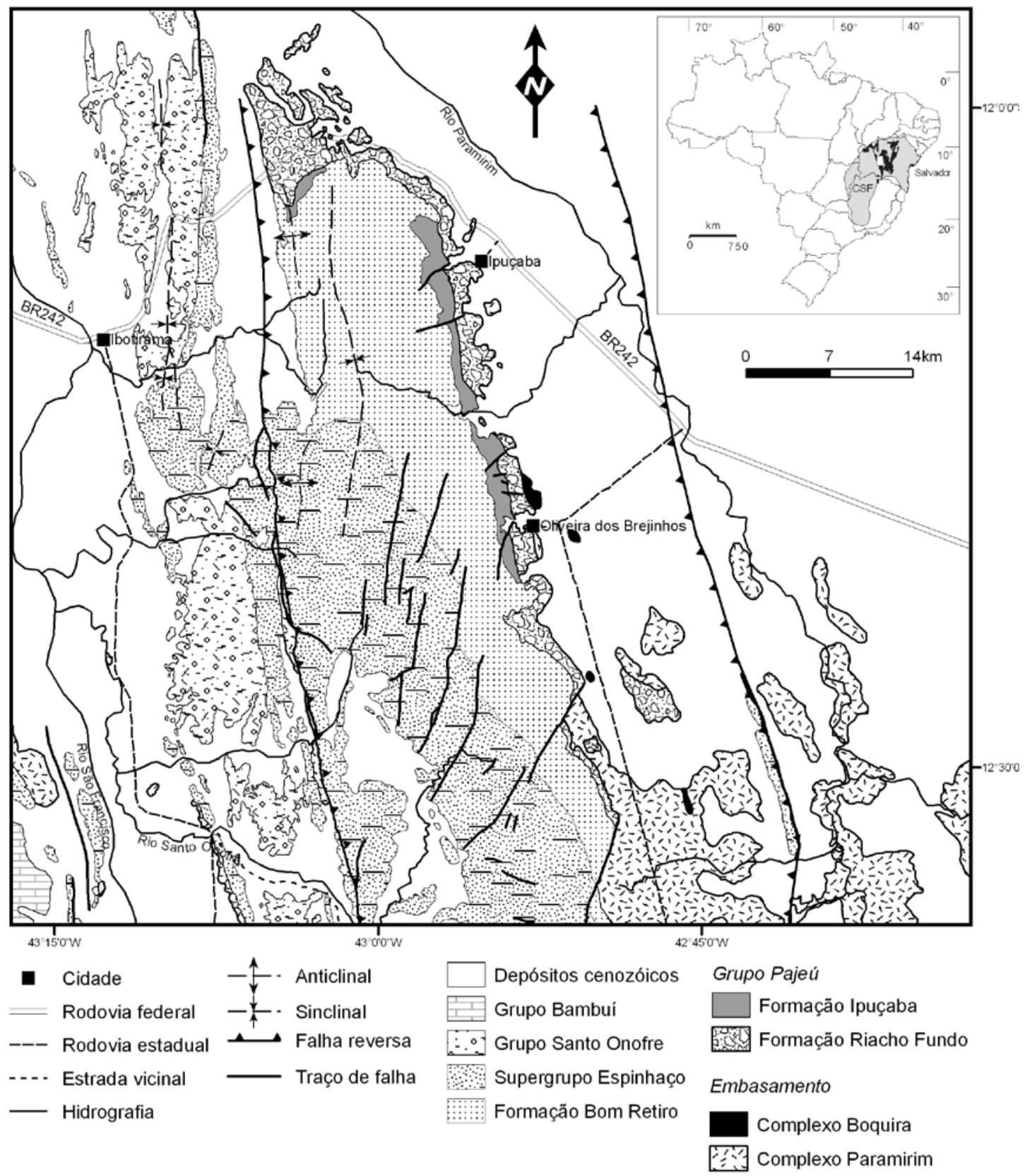

Figura 1 - Mapa geológico simplificado do Espinhaço Setentrional (modificado de Danderfer 2000). 
sidade, respectivamente. As amostras fazem parte do banco de dados do "Projeto Tectônica e Estratigrafia do Espinhaço Setentrional", coletadas durante a realização do projeto de doutorado de Danderfer (2000).

MATERIAIS E MÉTODOS Os estudos laboratoriais foram conduzidos nos laboratórios de Difração de Raios-X, Microscopia Ótica e Microanálises do Departamento de Geologia da UFOP. As análises de microsssonda foram realizadas no Laboratório de Microanálises do Instituto de Física da Universidade Federal de Minas Gerais, utilizando-se um equipamento da marca JEOL, modelo JCXA - 8900 RL, que operou com uma aceleração de $15 \mathrm{Kv}$ e corrente de feixe de $20 \mathrm{nA}$. Os padrões utilizados nas análises pertencem à coleção Ian Steele. As lâminas delgado-polidas foram metalizadas com uma película de carbono, para análise dos seguintes minerais: plagioclásio, anfibólio, epídoto e granada. Para o cálculo da forma estrutural dos minerais, resultados da microssonda foram trabalhados com o auxílio do Programa Minpet 2.0.

\section{ARCABOUÇO ESTRATIGRÁFICO DO RIFTE} PAJEÚ A sucessão estratigráfica do Grupo Pajeú, como cartografada por Danderfer (2000), ocorre segundo uma faixa submeridiana, longa e estreita ao longo da borda leste do Espinhaço Setentrional, dividida em dois segmentos: meridional e setentrional (Figs. 1 e 5). O seu arcabouço estratigráfico foi revisado e formalizado por Danderfer \& Dardenne (2002), que distinguem da base para o topo três unidades cartografáveis, cada qual com características sedimentares próprias e natureza distinta, definindo o preenchimento de um rifte. Da base para o topo, têm-se as formações Riacho Fundo, Ipuçaba e Bomba.

No segmento setentrional, alvo do presente estudo, o Grupo Pajeú jaz em discordância sobre gnaisses bandados do Complexo Paramirim e sequências sedimentares da Formação Boquira, ambos de idade arqueana e integrantes do bloco Gavião (Delgado et al. 2004). A superfície de contato se encontra preservada por toda a extensão da área, sem imposição significativa de deformação (Danderfer 2000). O limite superior é estabelecido de forma brusca com arenitos eólicos da Formação Bom Retiro (Schobbenhaus 1972, Dominguez 1993, Danderfer 2000), sob forma de uma descontinuidade sedimentar, tal como caracterizado por Danderfer \& Dardenne (2002). A idade máxima desta unidade é estimada em 1,56 Ga (Danderfer et al 2009).

A Formação Riacho Fundo, reconhecida a princípio por Kaul (1970 apud Schobbenhaus 1972), é composta de conglomerados e arenitos feldspáticos com estratificações cruzadas diversas. O seu acervo sedimentar foi depositado em sistemas de leques aluviais, fluvial tipo braided e eólico "seco" de interior continental (Danderfer 2000). A Formação Ipuçaba foi introduzida por Danderfer (2000) para agrupar rochas clásticas de granulação fina (arenitos finos a muito finos e pelitos interestratificados), originadas a partir de um sistema delta-lacustrino retrogradacional. As formações Riacho
Fundo e Ipuçaba definem uma pilha de fácies terrígenas, com tendência de granodecrescência ascendente, associada a um afinamento das camadas em direção ao topo.

A Formação Bomba, reconhecida por Kaul (1970 apud Schobbenhaus 1972), reúne rochas vulcânicas de caráter intermediário a ácido (quartzo traquitos, álcali-traquitos, latiandesitos e, subordinadamente, riolito pórfiros; Moutinho da Costa \& e Silva 1980, Fernandes et al. 1981), vulcanoclásticas e clásticas, aflorantes apenas no segmento meridional (Danderfer 2000). Jardim de Sá (1978) caracterizou o vulcanismo desta unidade como do tipo alcalino, com afinididade comendítica e elevados teores de $\mathrm{Rb}, \mathrm{Nb}, \mathrm{Zr}, \mathrm{La}$ e $\mathrm{Y}$, enquanto $\mathrm{Ba}$ e $\mathrm{Sr}$ são baixos, resultados estes que favorecem a interpretação de um ambiente extensional. Danderfer (2000) verificou uma passagem transicional entre as fácies lacustre da Formação Ipuçaba e os derrames de lavas em meio subaquoso da Formação Bomba. A idade desse vulcanismo foi estimada pelo método U-Pb em torno de 1,57 Ga por Danderfer et al. (2009).

No geral, o arcabouço litofaciológico do Grupo Pajeú é marcado por intensas variações faciológicas tanto verticais como laterais que, apesar disso, podem ser previsíveis dentro da arquitetura de uma bacia do tipo rifte (Danderfer 2000). Diques e soleiras de rocha básica (gabro e diabásio) ocorrem alojadas nessas seqüências, sobretudo no segmento setentrional da unidade. Há duas idades obtidas para o magmatismo básico na região, a saber: $1204 \pm 58 \mathrm{Ma}(\mathrm{K}-\mathrm{Ar}$ em rocha total, Távora et al. 1967; recalculado por Brito Neves et al. 1980) e $854 \pm 23 \mathrm{Ma}$ (U-Pb, Danderfer et al. 2009).

No segmento setentrional, as rochas do Grupo Pajeú são praticamente isentas de deformação; em certos locais, observa-se apenas uma clivagem incipiente em ângulo elevado com o acamamento. No setor meridional, por sua vez, a deformação apresenta um caráter mais penetrativo e marcante nas rochas, com desenvolvimento de clivagem em baixo ângulo com o acamamento sedimentar. As espessuras estimadas na parte norte são variáveis, todavia aumentam de forma progressiva em direção a norte, chegando a alcançar 2.500 $\mathrm{m}$. No segmento meridional, as espessuras aumentam em direção a sul até atingirem valores acima de 3.000 $\mathrm{m}$. Por conseguinte, os depocentros da unidade situamse próximos às extremidades sul e norte dos segmentos meridional e setentrional, respectivamente. Danderfer (2000) interpretou os dois compartimentos como dois hemigrábens, com bordas de falha situadas nas extremidades sul e norte, respectivamente.

Parte relevante das seqüências sedimentares do Grupo Pajeú, aflorantes principalmente na parte norte, foi considerada por Moutinho da Costa \& Silva (1980) como rochas derivadas de metamorfismo de contato. De modo característico, as rochas apresentam uma coloração esverdeada, que varia de clara a escura. Os autores interpretam as rochas intrusivas básicas na região como causador do metamorfismo. Por outro lado, Danderfer (2000) emprega o termo hidrotermalismo "verde" para se referir ao processo hidrotermal que afetou as rochas nesse local. Â exceção de algumas partes basais da For- 
mação Bom Retiro, as unidades estratigráficas mais jovens não apresentam qualquer indício desta atividade.

CARACTERÍSTICAS MACROSCÓPICAS Durante levantamentos de campo na porção norte do rifte Pajeú foram observadas diversas feições relacionadas com alteração hidrotermal, tanto em escala de afloramento como de amostra de mão, bem como algumas relações indicativas do estilo de circulação de fluidos associados. De forma característica, a manifestação desse processo é revelada pela coloração esverdeada adquirida pelas rochas ou pelo material de preenchimento existente ao longo de planos de anisotropia (fraturas e estratificação). Assim, utilizou-se o critério de cor para perceber quais rochas sedimentares exibiam alteração hidrotermal, ou não. Arenitos e matriz de conglomerados não alterados exibem cores variando de clara a rosada; já os pelitos, apresentam cores castanhas a cinza escuras. Quando alteradas, essas rochas mostram cores esverdeadas, com tonalidades variando de clara e muito escura.

Este aspecto vem sendo utilizado por alguns mineradores para explorar rochas ornamentais na região, principalmente conglomerados de cor esverdeada. Dessa forma, no decurso do levantamento de seções estratigráficas, observou-se que os efeitos do hidrotermalismo se restringiam apenas às unidades do Grupo Pajeú. Uma exceção a isto ocorre em alguns locais na base do pacote de fácies eólica da Formação Bom Retiro, onde se manifestava certa coloração esverdeada; o restante da seção se encontra inalterada pelo hidrotermalismo. Os efeitos mais significativos foram observados em fácies sedimentares da Formação Ipuçaba na parte norte da área, o que levou Moutinho da Costa e Silva (1980) a classificar essas rochas como hornfels, atribuindo-lhes uma origem por metamorfismo de contato, a partir da intrusão de rochas básicas.

Os efeitos do hidrotermalismo estão presentes em qualquer tipo de rocha, incluindo arenitos, pelitos, conglomerados do Grupo Pajeú e rochas cristalinas do embasamento, não havendo uma preferência para percolação nem para fixação dos componentes fluidais. As observações de campo mostram que os fluidos hidroter- mais percolaram através de fraturas e mesofalhas presentes tanto no embasamento quanto na cobertura ou ao longo dos planos de estratificação e através do espaço poroso das rochas sedimentares (Fig. 2).

Em amostra de mão, sob lupa ou mesmo a vista desarmada, foi possível reconhecer minerais de origem não sedimentar, relacionados com a alteração hidrotermal, a saber: epídoto, granada, anfibólio, quartzo e pirita. O epídoto se encontra disseminado na matriz de praticamente todas as rochas sedimentares do Grupo Pajeú, ou formando material de preenchimento de fraturas e planos de estratificação. O quartzo e o anfibólio também ocorrem disseminados, porém suas identificações são mais difíceis ou, de outra sorte, estão presentes em menor volume na rocha. Em alguns locais foram encontrados veios centimétricos a métricos de quartzo e anfibólio verde fibroso, encaixados em arenitos da Formação Riacho Fundo. O quartzo apresenta cor esverdeada e, em alguns locais, é extraído como material gemológico por garimpeiros.

A granada e a pirita são mais freqüentes no extremo norte da área, onde aparecem disseminados na matriz de conglomerados intensamente hidrotermalisados. Há ainda material carbonático presente na matriz das rochas sedimentares, detectado pela efervescência sob ataque de ácido clorídrico diluído; trata-se de calcita (efervescência a frio sem necessidade de pulverização do material), supostamente oriunda do hidrotermalismo. Apesar da alteração hidrotermal os aspectos sedimentológicos das rochas sedimentares pertencentes ao Grupo Pajeú acham-se bem preservados, o que tornou possível o reconhecimento de texturas clásticas e estruturas sedimentares. No entanto, em alguns horizontes de arenitos da Formação Riacho Fundo e pelitos da Formação Ipuçaba ocorrem zonas mais intensas de alteração hidrotermal, mascarando a trama sedimentar original e conferindo uma cor verde escura a preta à determinas faixas da rocha.

ANÁLISE PETROGRÁFICA Foram investigadas sob microscópio diversas amostras da matriz de conglomerados e arenitos, além de pelitos, coletadas no se-
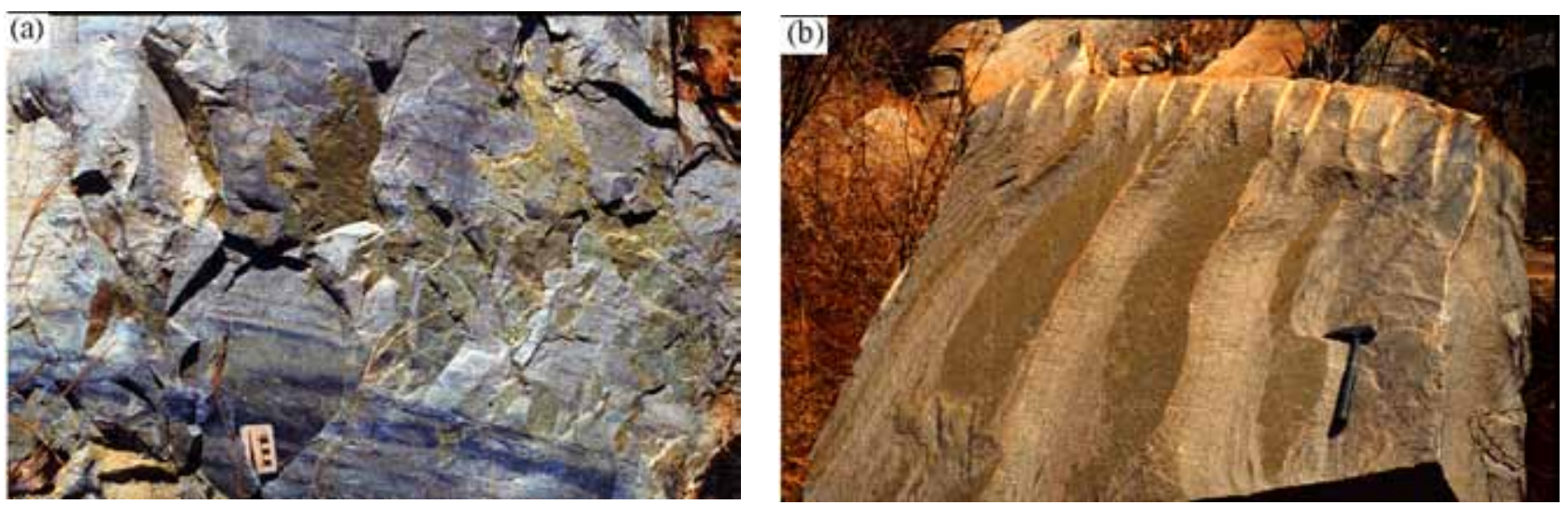

Figura 2 - Efeitos do hidrotermalismo, (a) ao longo de fraturas em ritmitos da Formação Ipuçaba e, (b) ao longo de planos de estratificação em arenitos eólicos da Formação Riacho Fundo. 
tor setentrional do Grupo Pajeú onde a deformação e o metamorfismo são incipientes. De forma geral, os tipos petrográficos apresentam granulometria e maturidade textural variáveis em função da natureza do ambiente deposicional. Os arenitos e a matriz de conglomerados são predominantemente arcosianos, compostos por grãos de feldspato alcalino e plagioclásio, frequentemente sericitizados ou saussuritizados, além de quartzo. De forma subordinada, ocorrem rutilo, apatita, mica branca, biotita e opacos. Nos arenitos de fácies eólica percebe-se uma nítida bimodalidade granulométrica e os grãos do arcabouço são predominantemente arredondados e bem selecionados, exibindo um empacotamento que varia de normal a fechado e com predomínio de contados suturados e côncavo-convexos entre os grãos; a maturidade textural é alta e a mineralógica é média.

Como produto da fase eodiagenética dos arenitos registra-se a compactação mecânica evidenciada pela rotação dos grãos rígidos do arcabouço. Durante a mesodiagênese houve a formação de sobrecrescimentos de quartzo e feldspato, dissolução por pressão, cimentação por calcita, dolomitização incipiente além de fases diagenéticas tardias como pirita e clorita.

A maior parte das rochas analisadas exibe efeitos de um intenso processo metassomático gerado por soluções hidrotermais, responsáveis pela formação de granada, anfibólio, epídoto, titanita, quartzo e albita no espaço poroso da rocha. A granada é a andradita que ocorre tanto preenchendo os poros da rocha como em agregados poiquilotópicos que envolvem vários grãos do arcabouço. Os cristais são euédricos a subédricos, possuem dimensões que variam de 0,2 a $1,0 \mathrm{~mm}$ e apresentam frequentemente estrutura zonada e caráter anisotrópico anômalo (Figs. 3a,b).

Dois tipos de anfibólio foram descritos: a tremolita e a actinolita. Ambas as fases minerais ocorrem com hábitos prismáticos a aciculares, euédricos a subédricos e ocupam o espaço poroso da rocha (Fig. 3e).

O epídoto forma cristais de aproximadamente $0,1 \mathrm{~mm}$ que ocorrem associados a granada e ao anfibólio nos poros da rocha. Ocasionalmente o epídoto preenche microfraturas (Fig. 3f). A titanita ocorre na forma de agregados anédricos que de forma análoga a outros minerais hidrotermais preenchem os poros da rocha. Observa-se que os cristais de titanita apresentam dimensões maiores que as dos grãos do arcabouço, o que corrobora de forma inequívoca a sua origem hidrotermal (Fig. 3g). Registram-se ainda como fases hidrotermais o quartzo e albita que ocorrem sob a forma de finos agregados que também preenchem o espaço poroso da rocha (Fig. 3h). Análises de microssonda eletrônica comprovaram teores inexpressivos do componente anortítico do plagioclásio.

QUÍMICA MINERAL Nas tabelas 1 e 2 são mostrados os resultados das análises químicas e as fórmulas estruturais da granada. Observa-se que enquanto os teores de $\mathrm{CaO}$ e $\mathrm{MnO}$ são relativamente constantes, ocorre uma nítida substituição do $\mathrm{Al}$ pelo $\mathrm{Fe}$ na estrutura cristalina do mineral, gerando núcleos compostos essencialmente pela molécula andradita (até 98,36\%) e bordas nas quais o teor do membro grossularita atinge $35,89 \%$ (Tab. 3). Os teores dos membros almandina, espessartita e piropo podem ser considerados como inexpressivos.

A composição química e a forma estrutural dos

Tabela 1 - Composição química da granada.

\begin{tabular}{cccccccccc}
\hline Amostra & $\mathrm{SiO}_{2}$ & $\mathrm{TiO}_{2}$ & $\mathrm{Al}_{2} \mathbf{O}_{3}$ & $\mathbf{F e O}$ & $\mathbf{M n O}$ & $\mathbf{M g O}$ & $\mathbf{C a O}$ & $\mathbf{N a}_{2} \mathbf{O}$ & Total \\
\hline $18 \mathrm{C} 1 \mathrm{~B}$ & 37,52 & 0,16 & 7,11 & 20,21 & 0,34 & 0,00 & 32,52 & 0,01 & 97,87 \\
$18 \mathrm{C} 1 \mathrm{~N}$ & 36,34 & 0,04 & 0,34 & 27,87 & 0,27 & 0,00 & 31,69 & 0,04 & 96,59 \\
$18 \mathrm{C} 5 \mathrm{~B}$ & 37,57 & 0,08 & 7,70 & 18,83 & 0,33 & 0,01 & 32,78 & 0,00 & 97,30 \\
$18 \mathrm{C} 5 \mathrm{~N}$ & 36,63 & 0,00 & 0,80 & 27,52 & 0,23 & 0,00 & 32,10 & 0,02 & 97,30 \\
$65 \mathrm{C} 3 \mathrm{~B}$ & 37,25 & 0,07 & 5,18 & 21,70 & 0,35 & 0,00 & 32,91 & 0,01 & 97,47 \\
$65 \mathrm{C} 3 \mathrm{~N}$ & 36,47 & 0,01 & 0,24 & 27,72 & 0,25 & 0,07 & 32,17 & 0,00 & 96,93 \\
$65 \mathrm{C} 7 \mathrm{~B}$ & 36,99 & 0,35 & 2,59 & 25,39 & 1,26 & 0,00 & 31,15 & 0,01 & 97,74 \\
$65 \mathrm{C} 7 \mathrm{~N}$ & 36,91 & 0,02 & 0,32 & 28,12 & 0,13 & 0,00 & 32,10 & 0,00 & 97,60 \\
\hline
\end{tabular}

Tabela 2 - Fórmula estrutural da granada.

\begin{tabular}{cccccccccccc}
\hline TSi & TAI & Sum_T AIVI & $\mathbf{F e}_{3}$ & $\mathbf{T i}$ & $\mathbf{C r}$ & $\mathbf{S u m}_{-} \mathbf{A}$ & $\mathbf{F e}_{2}$ & $\mathbf{M g}$ & $\mathbf{M n}$ & $\mathbf{C a}$ \\
\hline 3,06 & 0,00 & 3,06 & 0,68 & 1,38 & 0,01 & 0,00 & 2,07 & 0,00 & 0,00 & 0,02 & 2,84 \\
3,08 & 0,00 & 3,08 & 0,03 & 1,98 & 0,00 & 0,00 & 2,01 & 0,00 & 0,00 & 0,02 & 2,88 \\
3,07 & 0,00 & 3,07 & 0,74 & 1,29 & 0,01 & 0,00 & 2,03 & 0,00 & 0,00 & 0,02 & 2,87 \\
3,08 & 0,00 & 3,08 & 0,08 & 1,93 & 0,00 & 0,00 & 2,01 & 0,00 & 0,00 & 0,02 & 2,89 \\
3,07 & 0,00 & 3,07 & 0,50 & 1,49 & 0,00 & 0,00 & 2,00 & 0,00 & 0,00 & 0,02 & 2,91 \\
3,08 & 0,00 & 3,08 & 0,02 & 1,96 & 0,00 & 0,00 & 1,98 & 0,00 & 0,01 & 0,02 & 2,91 \\
3,08 & 0,00 & 3,08 & 0,25 & 1,77 & 0,02 & 0,00 & 2,04 & 0,00 & 0,00 & 0,09 & 2,78 \\
3,10 & 0,00 & 3,10 & 0,03 & 1,97 & 0,00 & 0,00 & 2,01 & 0,00 & 0,00 & 0,01 & 2,89
\end{tabular}

Tabela 3 - Membros finais da granada.

\begin{tabular}{cccc}
\hline Andradita & Grossularita & Piropo & Espessartita \\
\hline 66,53 & 32,60 & 0,00 & 0,82 \\
96,36 & 3,06 & 0,00 & 0,58 \\
63,27 & 35,89 & 0,04 & 0,79 \\
96,06 & 3,26 & 0,00 & 0,56 \\
74,66 & 24,46 & 0,00 & 0,83 \\
98,76 & 0,33 & 0,30 & 0,61 \\
86,49 & 10,36 & 0,00 & 3,10 \\
98,36 & 1,32 & 0,00 & 0,32 \\
\hline
\end{tabular}



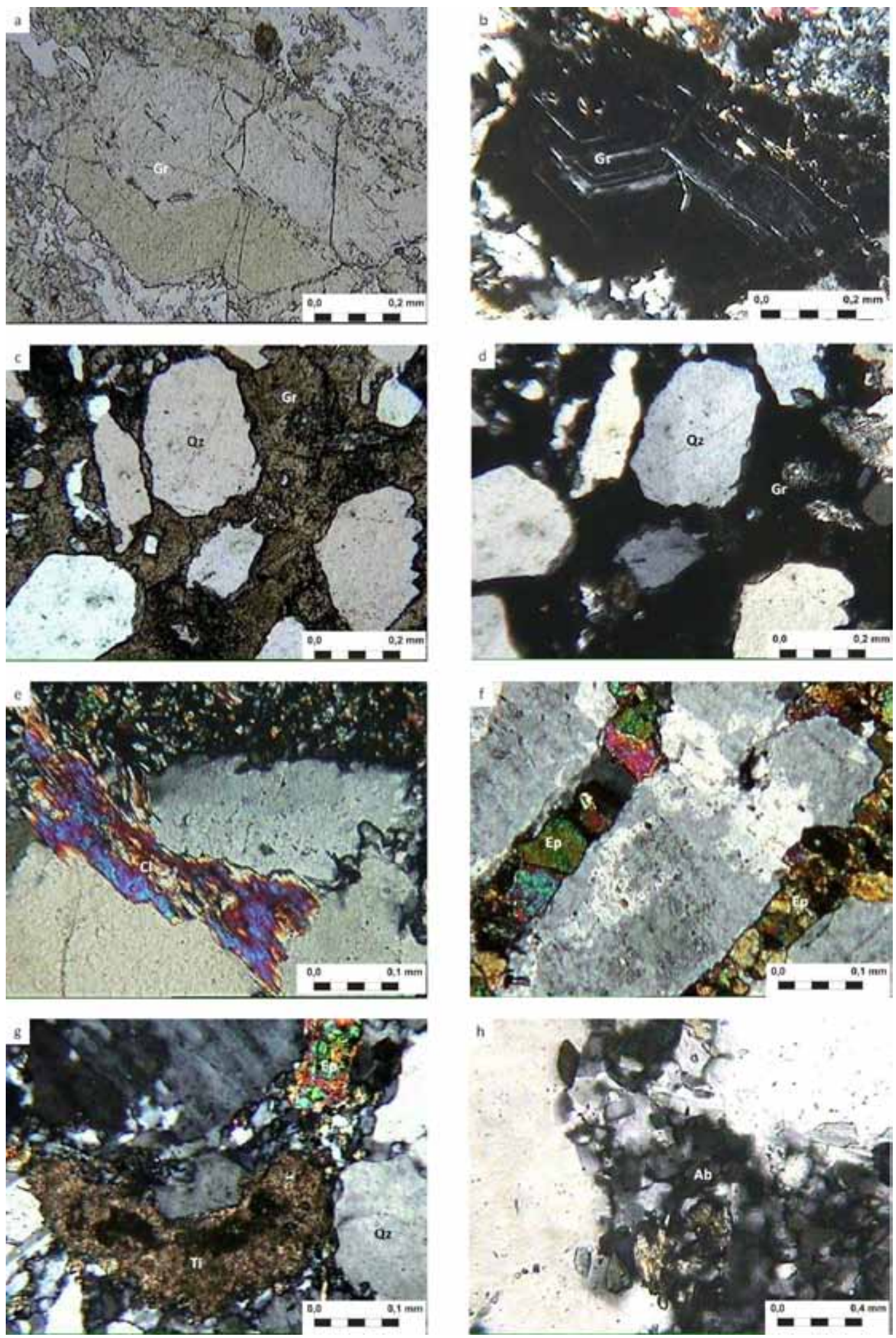

Figura 3 - Fotomicrografias de arenitos da Formação Riacho Fundo: a - Cristal zonado de andradita (Gr) hidrotermal sob luz plana. b - Cristal anterior sob nicóis cruzados, exibindo anisotropia anômala. c - Andradita hidrotermal (Gr) sob luz plana, envolvendo grãos detríticos de quartzo ( $Q z)$. d-Imagem anterior sob polarizadores cruzados. $e$ Cristal hidrotermal de clinoanfibóliocom polarizadores cruzados, preenchendo o espaço poroso da rocha. $f$ - Cristal hidrotermal de epídoto (Ep) com polarizadores cruzados, preenchendo microfraturas da rocha. $g$ - Cristal de titanita hidrotermal (Ti) com polarizadores cruzados, ocupando o espaço poroso da rocha. $h$ - Espaço poroso da rocha preenchido por albita $(A b)$. 
anfibólios estão representadas nas tabelas 4 e 5. Os dados, quando plotados no diagrama proposto por Leake et al. (1997), mostram variação da composição entre a da tremolita e a da actinolita (Fig. 4). Os resultados das análises químicas da tabela 6 mostram que o epídoto é da variedade rica em Fe e apresenta uma composição química homogênea, registrando-se apenas uma leve

Tabela 4 - Composição química do anfibólio.

\begin{tabular}{lllllllllll}
\hline Amostra & $\mathrm{SiO}_{2}$ & $\mathrm{TiO}_{2}$ & $\mathrm{Al}_{2} \mathrm{O}_{3}$ & $\mathrm{FeO}$ & $\mathrm{MnO}$ & $\mathrm{MgO}$ & $\mathrm{CaO}$ & $\mathrm{Na}_{2} \mathrm{O}$ & $\mathrm{K}_{2} \mathrm{O}$ & Total \\
\hline $22 \mathrm{C} 1 \mathrm{~N}$ & 58,97 & 0,00 & 0,41 & 1,69 & 0,15 & 23,78 & 12,86 & 0,30 & 0,01 & 98,17 \\
$22 \mathrm{C} 2 \mathrm{~N}$ & 54,40 & 0,00 & 1,25 & 3,00 & 0,12 & 16,79 & 24,02 & 0,46 & 0,00 & 100,04 \\
$22 \mathrm{C} 3 \mathrm{~N}$ & 53,43 & 0,06 & 1,43 & 3,64 & 0,12 & 16,59 & 23,28 & 0,58 & 0,03 & 99,16 \\
$22 \mathrm{C} 3 \mathrm{~N} 2$ & 58,98 & 0,01 & 0,46 & 1,80 & 0,07 & 23,75 & 12,47 & 0,33 & 0,06 & 97,93 \\
$65 \mathrm{C} 5 \mathrm{~N}$ & 57,41 & 0,03 & 0,68 & 7,76 & 0,33 & 19,54 & 12,06 & 0,43 & 0,10 & 98,34 \\
\hline
\end{tabular}

Tabela 5 - Fórmula estrutural do anfibólio.

TSi TAl $\mathrm{TFe}_{3}$ TTi Sum_T CAl CCr $\mathrm{CFe}_{3} \mathrm{CTi} \mathrm{CMg} \mathrm{CFe}_{2} \mathrm{CMn} \mathrm{CCa}$

$\begin{array}{lllllllllllll}7,99 & 0,03 & 0,00 & 0,00 & 8,01 & 0,04 & 0,00 & 0,10 & 0,00 & 4,80 & 0,06 & 0,01 & 0,00\end{array}$

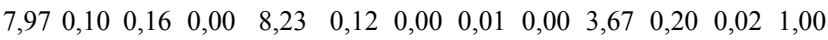

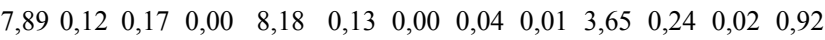

$\begin{array}{lllllllllllll}8,00 & 0,03 & 0,00 & 0,00 & 8,03 & 0,05 & 0,00 & 0,10 & 0,00 & 4,80 & 0,05 & 0,00 & 0,00\end{array}$

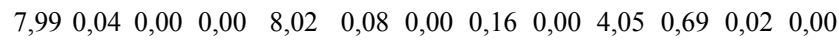

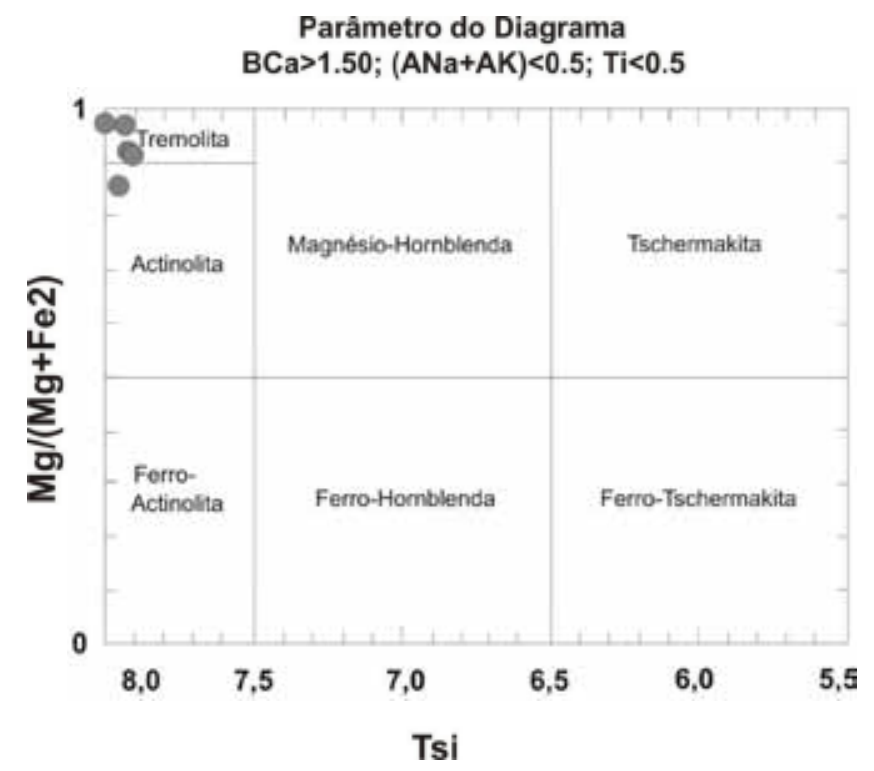

Figura 4 - Diagrama de classificação dos anfibólios segundo Leake et al. (1997). substituição do Ca pelo Fe (Tab. 7). Uma determinação de microssonda efetuada num agregado microcristalino de composição quartzo-feldspática, que preenche frequentemente os poros da rocha, mostrou que os teores de anortita do plagioclásio, inferiores a 0,9 podem ser considerados como irrelevantes (Tab. 8, 9 e 10).

Tabela 6 - Composição química do epídoto.

\begin{tabular}{llllllllllll} 
Amostra & $\mathrm{SiO}_{2}$ & $\mathrm{TiO}_{2}$ & $\mathrm{Al}_{2} \mathrm{O}_{3}$ & $\mathrm{FeO}$ & $\mathrm{MnO}$ & $\mathrm{MgO}$ & $\mathrm{CaO}$ & $\mathrm{Na}_{2} \mathrm{O}$ & $\mathrm{K}_{2} \mathrm{O}$ & Total \\
\hline $22 \mathrm{C} 3 \mathrm{~N}$ & 37,93 & 0,02 & 21,19 & 14,87 & 0,02 & 0,04 & 21,33 & 0,15 & 0,07 & 95,62 \\
$65 \mathrm{C} 1 \mathrm{~N}$ & 38,28 & 0,03 & 20,41 & 14,77 & 0,22 & 0,00 & 22,26 & 0,03 & 0,01 & 96,01 \\
$65 \mathrm{C} 4 \mathrm{~N}$ & 38,79 & 0,03 & 21,38 & 14,37 & 0,18 & 0,00 & 22,27 & 0,00 & 0,01 & 97,03
\end{tabular}

Tabela 7 - Fórmula estrutural do epídoto.

\begin{tabular}{lcccccccc}
\hline Amostra & $\mathrm{Si}$ & $\mathrm{Ti}$ & $\mathrm{Fe}_{3}$ & $\mathrm{Mn}$ & $\mathrm{Mg}$ & $\mathrm{Ca}$ & $\mathrm{Na}$ & $\mathrm{K}$ \\
\hline $22 \mathrm{C} 3 \mathrm{~N}$ & 2,934 & 0,001 & 0,96 & 0,001 & 0,001 & 1,768 & 0,022 & 0,007 \\
$65 \mathrm{C} 1 \mathrm{~N}$ & 2,958 & 0,002 & 0,95 & 0,014 & 0,000 & 1,843 & 0,004 & 0,001 \\
$65 \mathrm{C} 4 \mathrm{~N}$ & 2,956 & 0,002 & 0,91 & 0,012 & 0,000 & 1,818 & 0,000 & 0,001 \\
\hline
\end{tabular}

Tabela 8 - Composição química do feldspato.

Amostra $\mathrm{SiO}_{2} \quad \mathrm{TiO}_{2} \quad \mathrm{Al}_{2} \mathrm{O}_{3} \mathrm{FeO} \mathrm{MnO} \mathrm{MgO} \mathrm{CaO} \mathrm{Na}_{2} \mathrm{O} \mathrm{K}_{2} \mathrm{O}$ Total

$\begin{array}{lllllllllll}18 \mathrm{C} 3 \mathrm{~N} & 61,65 & 0,04 & 28,46 & 0,12 & 0,16 & 0,00 & 0,13 & 7,29 & 3,4 & 101,26\end{array}$

Tabela 9 - Fórmula estrutural do feldspato

\begin{tabular}{ccccccccccc}
\hline $\mathrm{Si}$ & $\mathrm{Al}$ & $\mathrm{Fe}_{3}$ & $\mathrm{Ti}$ & $\mathrm{Fe}_{2}$ & $\mathrm{Mn}$ & $\mathrm{Mg}$ & $\mathrm{Ba}$ & $\mathrm{Ca}$ & $\mathrm{Na}$ & $\mathrm{K}$ \\
\hline 10,76 & 5,85 & 0,00 & 0,01 & 0,02 & 0,02 & 0,00 & 0,00 & 0,02 & 2,47 & 0,76 \\
\hline
\end{tabular}

Tabela 10 - Membros finais do feldspato.

\begin{tabular}{ccc}
\hline $\mathrm{Ab}$ & $\mathrm{An}$ & $\mathrm{Or}$ \\
\hline 96,1 & 0,9 & 3,0 \\
\hline
\end{tabular}

DISCUSSÃO DOS RESULTADOS Como os arenitos do Grupo Pajeú não foram submetidos a eventos metamórficos, conclui-se que a paragênese mineral, que preenche o espaço poroso da rocha, representada 
por granada, anfibólio, epídoto, titanita, quartzo e albita foi originada por processos metassomáticos de intensidades variáveis.

A literatura geológica é pródiga em artigos que descrevem a ocorrência da granada andradita como produto de processos metassomáticos ou hidrotermais, mormente em escarnitos e tactitos. As variedades de andradita ricas em Ti, entretanto podem também constituir fase mineral primária típica de rocha vulcânicas ou plutônicas insaturadas em sílica, como observado por Russel et al. (1999), na cordilheira canadense. Esses autores discriminaram andradita de origem ígnea daquela de origem hidrotermal em função da substituição do Ti pelo Si na estrutura do mineral. Meinert et al. (2001) publicaram um trabalho pioneiro sobre datações U-Pb em andradita associada a processos de mineralização em escarnitos. Martínez-Serrano (2001) ao investigar paragêneses hidrotermais no sistema termal de Los Humeros, no Mexico, reporta a ocorrência de granada com percentagem da molécula de andradita de $98,36 \%$. A paragenêse mineral por ele estudada inclui ainda quartzo, calcita, caolinita, epídoto, zeólitas, actinolita, diopsídio, adulária, biotita, pirita, pirrotita, magnetita e hematita. A andradita foi também descrita por Livingstone (1989) como fase mineral secundária associada à zeólitas em lavas basálticas da Escócia. Stalder \& Rozendaal (2005) identificam o mineral calderita, uma solução sólida entre a andradita e espessartita, associada a sedimentos metamorfisados hidrotermalmente na fácies anfibolito, em depósitos de $\mathrm{Pb}$ e $\mathrm{Zn}$, na Africa do Sul. Ao contrário do que se observa com relação à maioria da granada de origem hidrotermal citada na literatura, a andradita descrita neste trabalho, preenche o espaço poroso de arenitos arcosianos e não possui qualquer relação com tactitos ou escarnitos.

O termo tactito, $($ do latim tactus $=$ contatar $)$ foi introduzido na literatura geológica por Hess (1919) ao estudar depósitos de tungstênio nas Groose Creek Montains, em Utah, nos EUA, para nomear rochas de mineralogia complexa geradas pelo metassomatismo de calcários. Já o termo escarnito (do sueco skarn = lixo), tem sido utilizado desde o Século XVIII pelos mineiros da Escandinávia para designar resíduos não aproveitáveis de mineralizações filoneanas, compostos essencialmente por silicatos ricos em Ca como granada, epídoto e anfibólio gerados pelo metassomatismo de calcários e dolomitos. A interação de fluidos hidrotermais, normalmente ricos em $\mathrm{Si}, \mathrm{Fe}, \mathrm{Al}$ e $\mathrm{Mg}$, com rochas carbonáticas possibilita frequentemente a formação da paragênese andradita-epidoto-tremolita. Em rochas siliciclásticas, entretanto, cujo teor em $\mathrm{Ca}$ é da ordem de apenas $3 \%$ (Turekian \& Wedepohl 1961, in Rösler \& Lange 1975), dez vezes inferior ao dos carbonatos, a formação da paragênese hidrotermal citada é relativamente rara.

Monteiro et al. (2008) realizando estudos geotermométricos no depósito de ouro e cobre de Sossego, na Serra dos Carajás, no Pará, identificaram a tremolita hidrotermal formada a temperaturas entre $300^{\circ} \mathrm{C}$ e $500^{\circ} \mathrm{C}$. A composição química dos cristais de anfibólios determinada pelos autores é semelhante à dos anfibólios hidrotermais dos arenitos do Grupo Pajeú.

$\mathrm{O}$ epídoto constitui uma fase comumente associada a processos hidrotermais. Boyce et al. (2003) ao pesquisarem a potencialidade geotermal de granitos da área de Lordello, na Itália, descreveram a formação secundária da paragênese clorita-quartzo-epídoto-albitatitanita preenchendo fraturas percoladas por fluidos com temperatura entre 340 e $450^{\circ} \mathrm{C}$. Keith et al. (1968) mencionaram a ocorrência da paragênese epídoto, quartzo, albita, Fe-actinolita e pirita gerada por soluções hidrotermais em sedimentos do Salton Sea na Califórnia. As análises químicas de duas amostras de epídoto realizadas pelos autores forneceram resultados idênticos aos das análises de microssonda realizadas neste trabalho.

Sarkar et al. (2008) reportam a ocorrência de albita pura associada ao quartzo, gerada por alteração hidrotermal de rochas gabróicas do Complexo de Bushveld, na África do Sul. Determinações microtermométricas em inclusões fluidas dos cristais de quartzo indicaram temperaturas da ordem de $500^{\circ} \mathrm{C}$. Junqueira et al. (2007) descreveram a paragênese albita-epídotoactinolita-calcita-quartzo associada à alteração hidrotermal de metabasaltos do Supergrupo Rio das Velhas na Mina de Raposos, no Quadrilátero Ferrífero.

Nos arenitos do Grupo Pajeú a albita ocorre associada ao quartzo sob a forma de diminutos cristais que ocupam os poros da rocha. O mineral deve ter sido formado numa fase final do evento metassomático, quando todo o cálcio existente na fase fluida, fora consumido na cristalização do epídoto, do anfibólio e da granada.

O hidrotermalismo "verde" pode ser interpretado como um evento que ocorreu nos estágios finais de formação do rifte Pajeú. A alteração observada em arenitos basais da Formação Bom Retiro sugere uma relativa contemporaneidade do processo hidrotermal com o início da sedimentação da unidade e término do evento. Os fluidos migraram através de zonas de fraturamento instaladas no embasamento e na cobertura sedimentar mais antiga do Supergrupo Oliveira dos Brejinhos. Em seguida, percolaram através de planos de estratificação e da porosidade primária de rochas siliciclásticas do Grupo Pajeú, depositando a paragênese mineralógica descrita anteriormente. Provavelmente as fraturas foram originadas durante a distensão crustal uma vez que Danderfer (2000) descreve falhas contemporâneas à sedimentação do rifte Pajeú. Percebe-se ainda que a intensidade do hidrotermalismo aumenta de sul para norte. No extremo setentrional ocorrem espessos depósitos de conglomerados, característicos de leques aluvionares de borda de falha, que exibem granada bem formada além de substituição total da matriz original por epídoto e anfibólio; sulfetos são igualmente visíveis nesse local. É bem possível que o aporte de fluido quente tenha ocorrido ao longo da falha mestra, favorecendo a deposição da paragênese completa de alta temperatura nas adjacência dessa falha.

Os efeitos mais significativos foram observados em fácies sedimentares da Formação Ipuçaba na parte norte da área, o que levou Moutinho da Costa e 
Silva (1980) a classificar essas rochas como hornfels, atribuindo-lhes uma origem por metamorfismo de contato, a partir da intrusão de rochas básicas. Todavia as investigações de campo revelaram algumas questões concernentes a tal gênese, entre as quais se observam:

i) Os aspectos sedimentológicos das rochas pertencentes à Formação Ipuçaba assim como de rochas de outras formações afetadas pelo hidrotermalismo acham-se bem preservados; não há uma alteração intensa e localizada da trama da rocha, como seria esperado em um hornfels (ou cornubianito) gerado por metamorfismo de contato;

ii) No intervalo estratigráfico afetado pelo hidrotermalismo "verde", são encontrados volumes substanciais de rochas afetadas pelo processo, porém situados a dezenas ou centenas de metros distantes das intrusivas básicas, consideradas como prováveis responsáveis pelo fenômeno; halos metamórficos de contato com extensões similares ocorreriam somente associados a intrusões de grandes dimensões, o que não procede;

iii) Não se observaram halos de metamorfismo ao redor das intrusivas básicas, sobretudo daquelas que se encontram encaixadas nas unidades líticas posicionadas acima do Grupo Pajeú. No entanto, esse fato talvez pudesse ser justificado pela existência de mais de um evento de magmatismo básico na região;

iv) Foram encontrados alguns corpos de intrusivas básicas encaixados no intervalo inferior do Espinhaço setentrional, com características petrográficas um tanto distintas das características dos corpos que sucedem acima do Grupo Pajeú e afetados também pelo hidrotermalismo; isso leva a crer que existiu realmente mais de um evento magmático de natureza básica na área estudada.

v) Verificam-se planos de fraqueza tanto em rochas da cobertura como do embasamento cristalino, preenchidos por material oriundo do hidrotermalismo "verde", principalmente epídoto, e não mostrando qualquer relação com as intrusivas básicas;

vi) Os efeitos do hidrotermalismo estão presentes em qualquer tipo de rocha, incluindo arenitos, pelitos, conglomerados do Grupo Pajeú e rochas cristalinas do Complexo Paramirim, não havendo uma preferência para percolação nem para fixação dos componentes fluidais.

Por essas razões, prefere-se desvincular a origem do hidrotermalismo de um metamorfismo de contato, embora ainda se considere que os fluidos possam ser contemporâneos ao emplacement de alguns corpos básicos, correspondendo assim a uma solução juvenil. Por outro lado, não é muito comum ocorrerem manifestações intensas de fluidos hidrotermais associados a magmas básicos, o que constitui uma questão importante a ser considerada. Além disso, a paragênese hidrotermal aqui caracterizada não é condizente com um ambiente dessa natureza.

É sugestivo que a fonte que originou os fluidos do hidrotermalismo "verde" esteja relacionada com um sistema subvulcânico, no qual o sistema hidrotermal se associa geneticamente a plutões subsuperficiais (Biondi 2003), portanto não aflorantes na região. A expressão em superfície desse sistema é evidente apenas no compartimento meridional do rifte Pajeú, onde afloram rochas vulcânicas intermediárias a ácidas da Formação Bomba datadas em torno de 1,56 Ga por Danderfer et al. (2009). A figura 5 ilustra as relações de contemporaneidade entre o magmatismo e o processo hidrotermal. No caso os fluidos ascenderam ao longo de falhas e fra-

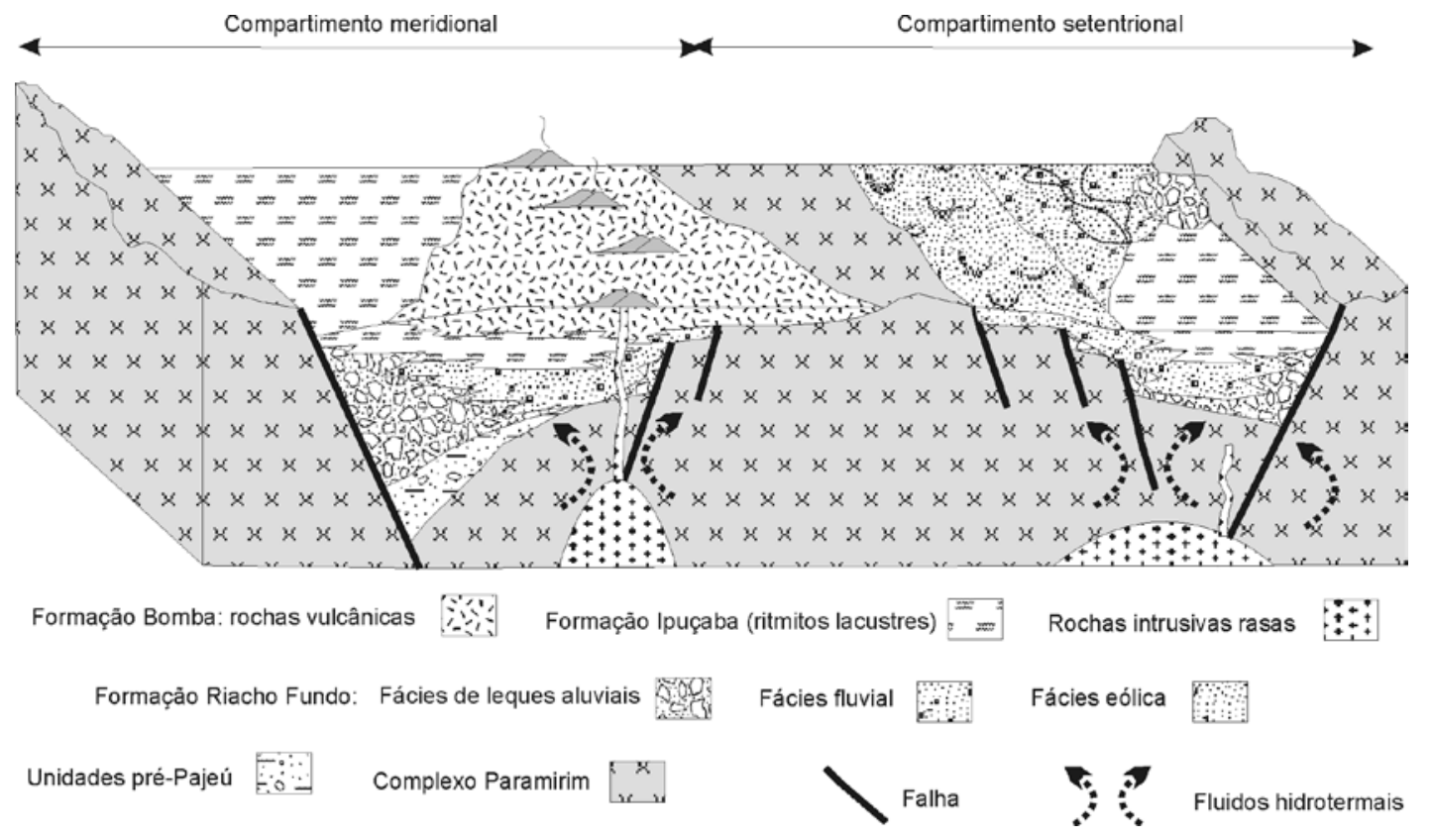

Figura 5 - Modelo esquemático mostrando o hidrotermalismo originado nos estágios finais do rifte Pajeú. 
turas através do embasamento até atingir os sedimentos de preenchimento do rifte. Deste ponto em diante, passaram a migrar através de fraturas e planos de estratificação ou percolando o meio poroso dos sedimentos e precipitando os minerais descritos neste trabalho.

CONCLUSÕES As relações de campo permitem inferir que (i) as rochas siliciclásticas do Grupo Pajeú aflorantes na porção nordeste do Espinhaço Setentrional não foram submetidos aos efeitos metamórficos e deformacionais tal qual em outros domínios e que (2) uma paragênese mineral rara, associada a processos hidrotermais, composta por tremolita, actinolita, granada andradita, epídoto, titanita, quartzo e albita foi reconhecida nos arenitos estudados.

A granada exibe anisotropia anômala e ocorre em cristais zonados, com $96,06 \%$ a $98,76 \%$ da molécula andradita no centro de alguns cristais e teores mais elevados da molécula grossulária, entre 10,36 e $32,60 \%$, nas bordas. Duas variedades de anfibólio foram reconhecidas: tremolita e actinolita, ambas preenchendo o espaço poroso da rocha. A forma euédrica e acicular dos cristais corrobora sua origem hidrotermal. O epídoto é da variedade rica em ferro e ocorre tanto ocupando o espaço poroso como preenchendo microfraturas da rocha. $\mathrm{O}$ fato de a titanita ocorrer em cris- tais maiores que os grãos do arcabouço que possuem menor densidade, conduz à interpretação do seu caráter hidrotermal e não detrítico. O elevado teor de sódio da albita e a sua associação com o quartzo sob forma de diminutos cristais que preenchem os poros da rocha, evidenciam o caráter hidrotermal do par mineral.

A origem do hidrotermalismo "verde" pode ser relacionada a um magmatismo intermediário a ácido, subaflorante, que deu origem às rochas vulcânicas da Formação Bomba na porção sul da bacia. Esse vulcanismo teria ocorrido nos estágios finais do rifteamento, sugerindo certo estiramento crustal para permitir a geração e o alojamento de magmas em níveis crustais elevados. Os fluidos quentes migraram ao longo de sistemas de falhas e fraturas extensionais, presentes no embasamento cristalino, e percolaram os sedimentos sin-rifte através de fraturas, planos de estratificação e do meio poroso.

Agradecimentos À Fapemig (processo $\mathrm{n}^{\circ}$ CEX864/96), pelo financiamento dos trabalhos de campo relacionados ao projeto "Tectônica e Estratigrafia do Espinhaço Setentrional", ao CNPq, pela cessão da bolsa de iniciação científica pelo programa PIBIC, e aos revisores da RBG pelas sugestões e críticas ao manuscrito, os sinceros e indeléveis reconhecimentos dos Autores.

\section{Referências}

Alkmim F.F., Brito Neves B.B., Alves J.A.C. 1993. Arcabouço tectônico do cráton do São Francisco - uma revisão. In: Dominguez J.M. \& Misi A. (eds.) O Cráton do São Francisco. Salvador, SBG/SGM/CNPq. p.45-62.

Almeida F.F.M. 1977. O Cráton do São Francisco. Rev. Bras. Geoc., 7:349-364.

Biondi J.C. 2003. Processos metalogenéticos e os depósitos minerais brasileiros. São Paulo, Oficina de Textos, 528 p.

Boyce A.J., Fulignati P., Sbrana A. 2003. Deep hydrothermal circulation in a granite intrusion beneath Larderello geothermal area (Italy): constraints from mineralogy, fluid inclusions and stable isotopes. Journal of Volcanology and Geothermal Research, 126:243-262.

Brito Neves B.B. de, Cordani U.G., Torquato J.R. 1980. Evolução geocronológica do Pré-Cambriano do Estado da Bahia. In: Inda H.A.V. \& Duarte F.B. (coords.) Geologia e Recursos Minerais do Estado da Bahia. Salvador, SME/COM, 3:1-101.

Danderfer A. 2000. Geologia Sedimentar e Evolução Tectônica do Espinhaço Setentrional. Tese de Doutoramento, Universidade de Brasília, Brasília, 498 p.

Danderfer A. \& Dardenne M.A. 2002. Tectonoestratigrafia da bacia Espinhaço na porção centro - norte do cráton do São Francisco: registro de uma evolução poliistórica descontínua. Rev. Bras. Geoc., 32:449-460.

Danderfer A. de Waele B., Pedreira A.A.J., Nalini Jr. H.A. 2009. New geochronological constraints on the geological evolution of Espinhaço basin within the São Francisco craton - Brazil. Precambrian Research, 170:116-128.

Delgado I.M., Souza J.D., Silva L.C., Silveira Filho N.C.,
Santos R.A., Pedreira A. J., Guimarães J.T., Angelim L.A.A., Vasconcelos A.M., Gomes I.P., Lacerda Filho J.V., Valente C.R., Perrotta M.M., Heineck C.A. 2003. Geotectônica do Escudo Atlântico (Capítulo V). In: Bizzi L.A., Schobbenhaus C., Vidotti R.M., Gonçalves J.H. (eds.) Geologia, Tectônica e Recursos Minerais do Brasil. Brasília, CPRM, p. 227-334.

Dominguez J.M.L. 1993. As coberturas do Cráton do São Francisco: uma abordagem do ponto de vista da análise de bacias. In: Dominguez J.M. \& Misi A. (eds.) O cráton do São Francisco. Reunião preparatória do II Simp. Sobre o Cráton do São Francisco. Salvador, SBG/Núcleo BA-SE/SGM/CNPq., atas, p. 137-159.

Fernandes P., Montes M.L., Bras G., Montes A., Silva L., Oliveira F., Ghignone J.I., Siga Jr. O., Castro H. 1982. Geologia. In: Ministério das Minas e Energia/SG, Projeto Radambrasil. Folha Brasília (SD.23). Brasília, 29:25204.

Hess F.L. 1919. Tactite, the product of Contact Metamorphism. The American Journal of Science, 2:377-378.

Jardim de Sá E.F. 1978. Geologia da Chapada Diamantina e Faixa Santo Onofre, e geoquímica do vulcanismo ácido associado. Dissertação de Mestrado, Instituto de Geociências, Universidade Federal da Bahia, Salvador, 180 p.

Junqueira P.A., Lobato L.M., Ladeira E.A., Simões E.J.M. 2007. Structural control and hydrothermal alteration at the BIF-hosted Raposos lode-gold deposit, Quadrilátero Ferrífero, Brazil. Ore Geology Reviews, 32:629-650.

Keith T.E.C., Muffler L.J.P., Cremer M. 1968. Hydrothermal epidote formed in the Salton Sea Geoothermal System, 
California. American Mineralogist, 53:1635-1644.

Leake B.E., Wooley A.R., Hawthorne F.C., Kato A., Krivovichev V.G., Laird J., Maresch W.V., Schumacher J.C., Stephenson N.C.N., Wittaker E.J.W., Youzhi G. 1997. Nomenclature of amphiboles of the International Mineralogical Associaton Comission on New Minerals and Mineral Names. Mineralogical Magazine, 61:295-321.

Livingstone A. 1989. Low-temperature, hydrothermal garnet associated with zeolites, from basalt lavas near Beith, Ayrshire. Mineralogical Magazine, 53:125-129.

Marshall L.J. \& Oliver N.H.S. 2008. Constraints on hydrothermal fluid pathways within Mary Kathleen Group stratigraphy of the Cloncurry iron-oxide-copper-gold District, Australia. Precambrian Research, 163:151-158.

Martínez-Serrano R.G. 2001. Chemical variations in hydrothermal minerals of the Los Humeros geothermal system, Mexico. Geothermics, 31:579-612.

Meinert L.D., Nicolessus S., Mortenses J.K., Cornell D.H. 2001. U-Pb dating of hydrothermal garnets from skarn deposits: implication for petrogenesis and ore deposits. In: Geol. Soc .Am., General Meeting, Boston, Abstracts, vol.1, p. 53.

Monteiro L.V., Xavier R.P. Hitzman M.W., Souza Filho C.R., Carvalho E.R. 2008. Mineral chemistry of ore and hidrothermal alteration of the Sossego iron oxide- copper-gold deposit, Carajas Mineral Province, Brazil. Ore Geology Reviews, 34:317-336.

Moutinho da Costa L.A. \& Inda H.A.V. 1982. O aulacógeno do Espinhaço. Ciências da Terra, 2:13-18.

Moutinho da Costa L.A. \& Silva W.G. 1980. Projeto Santo Onofre, mapeamento geológico. Rio de Janeiro, TRISERVICE, Convênio DNPM/CPRM. 21v., v.1. (Relatório Final).
Röesler H.J. \& Lange H. 1975. Geochemische Tabellen. 2. Auflage, Leipzig, INTERDRUCK Graphischer Grossbetrieb Leipzig, 674 p.

Russel J.K., Dipple G.M., Lang J.R., Lueck B. 1999. Majorelement discrimination of titanium andradite from magmatic and hydrothermal environments; an example from the Canadian Cordillera. European Journal of Mineralogy, 11:919-935.

Sarkar A., Ripley E.M., Li C. \& Maier W.D. 2008. Stable isotope, fluid inclusion, and mineral chemistry constraints on contamination and hydrothermal alteration in the Uitkomst Complex, South Africa. Chemical Geology, 257:29-138.

Stalder M. \& Rozendaal A. 2005. Calderite-rich garnet and franklinite-rich spinel in amphibolite-facies hydrothermal sediments, Gamsberg $\mathrm{Zn}-\mathrm{Pb}$ deposit, Namaqua Province, South Africa. The Canadian Mineralogist, 43:585-599.

Schobbenhaus C. 1972. Relatório geral sobre a geologia da região setentrional da serra do Espinhaço - Bahia Central. Nota explicativa do mapa geológico 1:250.000. Recife, SUDENE/DRN/Div. Geol. 91p. (Série Geologia Regional 19).

Távora F.I., Cordani U.G., kawashita K. 1967. Determinações de idade potássio-argônio em rochas da região central da Bahia. In: SBG, Cong. Bras. Geol., 21, Anais, p. 214-24.

Manuscrito ID 16964

Submetido em 04 de março de 2010 Aceito em 05 de outubro de 2010 